\title{
ENTRE RECITAL Y CHARLA: EL ACTO CREADOR Y UNOS APUNTES SOBRE "PENÉLOPE”
}

\author{
Marta Rojas Porras \\ Profesora de la Escuela de Filología y Lingüística y Literatura \\ Investigadora del INIE
}

\section{Recibido 29-X-2003 • Aceptado 9-III-2004}

\begin{abstract}
Resumen: Este texto expone algunas de mis ideas y experiencias como escritora y las ejemplifica con poemas de mi producción. Enmarcada en ese contexto; se plantea una lectura personal de mi poema Penélope, el cual se lee en décimo año de la Educación General Básica.
\end{abstract}

Palabras clave: Creación Literaria, Lectura, Poesía.

\begin{abstract}
This study expresses some of my ideas and experiences as a writer and is illustrated with poems of my own. Within this context, I offer a personal reading of my poem "Penélope" whose reading is assigned in the fourth year of public high school.
\end{abstract}

Key words: Literary Creations Reading, Poetry.

Con frecuencia, en las visitas a colegios, en conversaciones con jóvenes de décimo año, quienes leen una de mis poesías, Penélope, incluida en el programa oficial de Español, surgen preguntas sobre el acto de crear y, desde luego, preguntas sobre el poema en particular, o sobre mi poesía en general. Atendiendo esas inquietudes, he escrito este texto, donde expongo algunas de mis ideas y de mi experiencia, y las ejemplifico con poemas de mi producción. Además, planteo una lectura del poema Penélope y lo contextualizo en mi obra.

Porque considero que esta perspectiva podría ayudar a profesores y estudiantes, he cedido a la tentación de la sugerencia de algunos compañeros de publicarlo. Escojo este medio, la Revista Educación, pues aunque el texto se expone en términos literarios, considero que es a una porción de sus lectores, profesores de Español y estudiantes, a quienes les podría aportar algo mi visión.

Hablar sobre el acto creador y desde una perspectiva de creadora, irremediablemente me involucra en la totalidad de mi existencia privada y pública, intelectual y emotiva, pequeña y grande... 


\section{Intimidad}

¿Sabes que tus recuerdos/ traen habitantes a mi casa,/que los huelo, que los palpo/ y que converso con ellos?// ¿Sabes que eres roble,/ arbusto a la orilla de un río,/ ciprés que adorna mi techo,/ violeta en una ventana?// ¿Sabes que sueño tu mano/ conquistando mi cuello/ y el calor de tu pie/ sobre la frialdad de mi dedo?

De La sonrisa de Penélope y su costumbre del adiós

\section{Ronroneando}

Si me oyen ronronear/ no se asusten:/ Estoy feliz de cobijarme/ en su abrazo.

De La sonrisa de Penélope

y su costumbre del adiós

Como se nota, el detalle de lo cotidiano, lo íntimo, lo aparentemente insignificante, nutre la vida y es savia que alimenta la poesía, la cual también se alimenta de frustraciones y destiempos:

\section{Ocurre}

Ocurre/ que la vida entre papeles,/ informes, reuniones y cursos/ me arrebata el tiempo// Ocurre/ que los retoños de la plantita/ sobre mi escritorio/ pasan inadvertidas y sin cuidado.// Ocurre/ que la queja doliente y laberíntica/ de la compañera hastiada/ por la explotación doméstica/ y el trabajo rutinario/ no encuentra mi eco.// Ocurre/ que aplazo mi salida por esas calles/ para conversar con aquella niña de grandes ojos negros,/ y de mirada crecida de tristeza/ que anda, huraña, por ahí,/ vendiendo chicles o pidiendo limosna/ sin ir a la escuela.// Ocurre/ que la nota oficial del recibo telefónico:/ "Todo costarricense tiene derecho a la educación"/ sólo esboza en mí una sonrisa doliente/ por una intención de crítica pospuesta,// Ocurre/ que me desaniman/ los cambios que el maestro/ reconoce apenas en lo más evidente.// Ocurren/ tantos llantos,/ regocijos, soledades,/ agonías, victorias.../ que sólo han contado/ con mi propia ausencia... 
En el acto creador confluyen mis fantasmas y mis hadas, mis anhelos y mis frustraciones, mis amores y mis desamores, mis tiempos y mis destiempos, mis aciertos y mis desaciertos. En este sentido, el acto creador es análisis de mí misma, es fragmentación y desmenuzamiento; pero también es síntesis e integración. Pues sí, escribir, y sobre todo escribir poesía, es como desnudarse ante el mundo: la poesía es el lugar de la verdad y a ratos esa verdad incomoda.

\section{Mirar el mundo y tocarlo}

Me gusta/ caminar bajo la lluvia,/ fantasear con la gota danzante del charco,/ hablar con desconocidos/ y sorprenderme con sus mundos,/ hacer silencio alrededor del fuego,/ interpretar el chisporroteo de las llamas/ en su diálogo con el tizón, las cenizas y el humo,/ oler el clavel y el perejil,/ mirar el mundo y tocarlo.

De La sonrisa de Penélope y su costumbre del adiós

\section{Terrosidad}

Jineteando mi nostalgia/ buscaba el río de la infinita luna./ Su hilera laberinto me cerró el paso.// Perseguida persiguiendo/ me obstiné por el agonizante rayo,/ me abismé de impaciencia/ y reclute soledad.// Retrocedí,/ afronté mis propósitos/ y recuperé aquel río/ en el fresco riachuelo,/ en la cantarina acequia,/ en la leve llovizna de un aliento./ Tributé codicia por mi terrosidad/ y rescaté la esperanza.

De La sonrisa de Penélope y su costumbre del adiós

\section{En estos términos}

Ya no lo amo.//Y he amado a muchos después de haberlo amado a él.//Y he amado en grande.// Pero si hubiera podido,/ toda la vida lo habría amado a él.

De Aposentos del deseo

El acto de crear es un proceso que me lleva al monólogo y al diálogo, a conversar con mi propia otredad y a conversar con los otros. Crear es entrar al espacio privado a jugar con la propia sombra, que es una sombra construida con la sombra de otros. Crear es entrar al lugar que yo habito y al de los otros y, desde ahí, descubrir mis sombras que son también las sombras de los otros, desgarradas, entrelazadas, fundidas... El acto de crear es una ruta que me transita en una densa pluralidad de luz y penumbras, de ideas y revelaciones, de intimidades y colectivos. Es riqueza, es variedad.

Mi voz es mi propia voz; pero también es la voz o el eco de muchas mujeres $\mathrm{y}$, por qué no, de muchos hombres. 


\section{Mi voz}

Mi voz, murmullo de voces femeninas,/ maldice/ las descalificaciones arbitrarias,/ el implacable ninguneo,/ el acatamiento sumiso,/ la docilidad incuestionada.// Mi voz, galope de voces,/ denuncia/ los altares vanos de dioses masculinos/ custodiados/ por idólatras mujeres.// Mi voz, desafiante voz,/ grita/ que la infidelidad es mentira/ sin género.// Mi voz, conciliadora voz,/ aclama/ el afán de tempestades/ dominadas entre pares.// Mi voz, apasionada voz,/ invita/ a hacer el amor/ desnudos de cuerpo y alma.// Mi voz, anhelante voz,/ declara/ su amor al otro/ en su dimensión igualitaria.// Mi voz, inclaudicable voz,/ añora/ encontrar el eco/ que prolongue su esperanza.

De Aposentos del deseo

El acto de crear es también un proceso que me lleva a compartir con la extrañeza y lo sorprendente, a buscar respuestas que no son respuestas y que devienen en más búsquedas, a debatirme entre el vacío y el silencio. Es incomodarse no sólo con la existencia y las circunstancias, sino también combatir con la palabra y con el significado. Crear es, entonces, trabajo, lucha, ensayo, reflexión, indagación sobre el ser humano, sus sentidos y sinsentidos. Es, básicamente, poetizar sobre nuestra condición, sobre nuestra incompletud, sobre nuestra soledad, sobre lo inconquistable, sobre las ausencias y las búsquedas, sobre las esperanzas... Es un compromiso con la integridad, con el pensamiento, con el corazón. Es un acto de sinceridad y confrontación.

\section{Conspiración}

Desde el crepúsculo/ la oscuridad amenaza.// De noche, vestida de inocencia/ irrumpe en carruajes de supermanes/ y mujeres maravilla.// Agrede la fantasía/ con final de fotonovela,/ con tarareos en idiomas no entendidos.// Se están secando nuestros ríos,/ calla el yigüirro en la montaña.// Desde mi pecho un niño llora,/ un adolescente tienta penumbra,/ una madre cabizbaja deambula,/ un maestro se extravía en la encrucijada.// ¿Cómo hallar en este invernal frío/ un rescoldo que arda?// Mi briosa guitarra/ con voz quebrada,/ con susurros,/ fuertemente,/nos persuade:/ nos roban la leyenda, la ronda,/ el quedó, el escondido;/ conspiran contra la imaginación, la vapulean;/ encarnecen la esperanza/ y aletargan al potro que galopa en cada hombre.// ¿Cómo buscar/ en el azul amargo de este verano/ el rayo del alba?

De La sonrisa de Penélope y su costumbre del adiós

\section{Hábito}

Quisiera desalojar/ de mi aposento/ el hábito de las ausencias. 
Miento

¡Soy collado!// Cerro menos que monte.../ paso de sierras.../ árboles .../ vaivén... / voces.../ relatos...// ¡Miento!// Sin el amor de un hombre,/ algo en mí es caverna.

De Aposentos del deseo

\section{Mi debate}

Entre el recuerdo infantil/ de prima descalza y tío comiendo salteado.// Entre jugar a hacer poesía/ desde el cafetín de la universidad/ o conocer el sudor/ y cantarlo.// Entre el ayer y el ahora,/ el ahora y el después.// Entre vivir de fiado/ o pagar la cuota.// Entre la arena/ y su grano.// Entre Cenicienta/ y Ser.

De La sonrisa de Penélope y su costumbre del adiós

Escribir es un proceso de compromiso y apropiación creadora de los otros para alcanzar mi propia voz. Esto es, se escribe en el mundo y desde el mundo, desde la propia conciencia y el imaginario colectivo, desde el lenguaje y su silencio, su insuficiencia, desde lo dicho y lo innombrable, desde la contemplación y desde las realidades, desde los juegos de sortilegios y escondidos, del quedó y las tinajas rotas y vacías.

\section{Prisionera de la esperanza}

¡Señor, a vos clamo!// La soberbia de los humanos se ensancha./ ¡Me asfixio!// Los bosques perecen./ Los ríos se secan./ Los mares ya no rugen.// La noticia de violencia,/ destrucción y contienda/ deambula/ como huracán devastador/ que no se sacia.// El ruido me aturde./ El temor me aguijonea./ Un golpe seco de desierto/ golpea mi ventana.// ¡Mis tiendas están en aflicción!/ ¡Socórreme!// Sé/ que un viento/ más vehemente que este/ vendrá,/ pero tu gozo/ reforzará/ los cimientos de mi casa,/ restaurará las grietas de las paredes,/ y tu mano refugiará a los míos del aguacero.// ¡No tardés!,/ porque yo,/ testigo de una generación/ que despoja a sus hijos de la heredad,/ me declaro/ prisionera de la esperanza.// ¡En vos confío!

De Habitar la casa del tesoro

Si bien quien escribe cuenta con una tradición literaria, un juego de sentidos, las condiciones políticas, las programaciones culturales de lectura y de interpretación; a la hora de crear, este aparato ideológico opera inconscientemente, pues aunque parte de un colectivo, en el acto creador como tal, el autor o autora construye un gesto estrictamente individual y privado, lo cual hace posible que, a pesar de las repeticiones, el carácter de la creación sea particularmente productivo y original. Como dice Octavio Paz: 
"No hay principio, no hay palabra original, cada una es una metáfora de otra palabra que es una metáfora de otra palabra que es una metáfora de otra y así sucesivamente."

El acto de creación es una interpretación y comprensión del mundo hecha a partir de una experiencia, una historia, unos anhelos, unos imaginarios que transitan al poeta o a la poeta. En este sentido, la creación es colectiva. Pero como acto es también un acto individual donde, en un proceso de conciencia y apropiación, quien escribe interpreta, reelabora, integra, sintetiza, recrea y crea.

\section{Penélope}

Si hay que decir adiós, se dice./ Si hay que llorar, se llora./ ¡Todo tiene su tiempo!// Hoy,/ con la aguja de mi reloj,/ con las puntadas del esfuerzo,/ el amor,/ los besos,/ con el hilo vivido,/ tejo./ ¡Este es mi tiempo!// Mañana,/ con las mismas agujas,/ con las mismas puntadas,/ con el mismo hilo,/ con toda mi voluntad,/ mi pericia y mi cuidado,/ tal vez, como Penélope, desteja.

\section{De La sonrisa de Penélope} y su costumbre del adiós

"Penélope" debe de ser mi poema más leído. Para muchos, una lectura obligatoria; para otros, espero que, si no voluntaria, al menos de algún provecho o placer. Alrededor de este poema, por la condición dicha, surgen una serie de preguntas y comentarios. Lo que sigue es mi lectura de "Penélope", simplemente una lectura más y, probablemente, la de menor peso.

Tres textos de la tradición cultural transitan este poema: El texto bíblico, Eclesiastés 3:1-8 "Todo tiene su tiempo", el texto griego con la Penélope de Homero y el texto feminista o la teoría de género de nuestra época.
El texto bíblico sirve de marco categórico que permite una entrada decidida y valiente: Si hay que decir adiós, se dice./Si hay que llorar, se llora./ ¡Todo tiene su tiempo!/. Retomo el texto bíblico y lo reproduzco en otro contexto; pero éste, básicamente, conserva su sentido.

El tiempo del yo lírico es el del presente: Hoy/... Este es mi tiempo/ Un tiempo de besos, de esfuerzos en el que se teje el amor y en el que el pasado está presente como "el hilo vivido", como la experiencia.

Al pasado se va sólo como memoria de tránsito, como germinación del presente y magia de la meta que se construye, pues, según el final del poema. 
El pasado

Los ojos con que lo miremos/ deben penetrarlo/ con ávida mirada de viajero en tránsito,/ sin el horror de la nauseabunda mutilación del pantano/ y con la precaución de ver hacia atrás/ sin convertirnos en estatuas de sal.

De La sonrisa de Penélope y su costumbre del adiós, fragmento.

El mañana es también un tiempo para tejer el amor o el desamor; pero siempre en una tela propia que se construye con trabajo, con esfuerzo y con voluntad inclaudicable: Mañana/con las mismas agujas,/con las mismas puntadas,/con el mismo hilo, / con toda mi voluntad, mi pericia y mi cuidado...

Aparece un discurso modal: ...tal vez, como Penélope, desteja. Ese tal vez marca al verbo destejer en oposición a tejer, pero ambos como acciones dinámicas. Tal vez se teja o tal vez se desteja, pero el yo lírico no duda en ser la hacedora del propio camino.

Otro texto es el relato griego de $L a$ Odisea, de Homero, de donde se extrae la figura de Penélope, arquetipo de la mujer de la casa, que espera, la mujer de un solo marido, que ama a un único hombre a pesar de su ausencia o su abandono y a expensas de sus propios anhelos, la mujer que teje su propia soledad y dependencia.

Ese personaje se toma y se contextualiza en un entorno que muestra una actitud diferente, contraria: Una mujer que así como construye el amor, con igual dignidad podría estar construyendo el adiós o la partida.
Esta Penélope es una Penélope, una mujer que toma decisiones, una mujer que quiere contar con el otro porque primero cuenta consigo misma. Una mujer para la que su propia dignidad está primero. Posición que nos conduce a otro texto cultural sobre las teorías del género.

Como se observa, el poema corresponde a una visión de mundo en la que se concibe el papel de la mujer como un ser activo, que toma decisiones por sí misma y que se atreve al riesgo. En este sentido, frente a la "Penélope" ancestral de Homero, aquella que teje y desteje esperando al marido que salió al mundo en busca de aventuras, esta "Pénelope" es una transgresora.

Una mujer que ama y que construye ese amor, que teje con la fortaleza que le da lo vivido. Dice: “¡Este es mi tiempo! , y lo dice con convicción y gozo. Pero, además, sabe que si tuviera que enfrentar otras circunstancias, igual lo podría hacer, aunque no sea fácil. Esta Penélope no es sólo la amada, es también la amante, la que ama activamente y es dueña de pasiones, de sus anhelos, de su vida.

En este sentido, esta es una Penélope erótica, activa, apasionada y, en esto, también transgresora:

\section{Moldeo un cántaro}

El sol empieza a levantarse.// Tiro a la intemperie las telarañas y el silencio./ Atravieso las sombras y sus muecas.//Moldeo,/ con las brazas de tu taco,/ con el tizón que soplamos,/ con el barro primigenio,/ con el musgo de mis vértices,/ con la humedad de mis poros,/ un cántaro./ iy lo lleno de la sonrisa que se hace en mí!// Entrelazo mis piernas con las tuyas/ y en contacto con mi tibio hueco/ te anido en cada una de mis honduras.

De La sonrisa de Penélope y su costumbre del adiós, fragmento. 
Vale la pena recordar un cuarto texto: el de tejer con hilo y agujas. Cualquiera que se halla enfrentado a este quehacer sabe el infinito cuidado que debe tenerse al destejer y que, cuando la prenda no está quedando bien o nos hemos equivocado, se hace necesario destejer, a riesgo de que, al halar una hebra, se nos deshaga toda la labor o se nos dificulte el continuar.
Si comparamos la vida con un tejido, a veces es imprescindible, también, destejerla: hacer altos en el camino, evaluar el pasado para continuar la marcha, decir adiós, vivir los duelos y restaurarse de las heridas. Sólo así podremos enfrentarla con un corazón sano, agradecido. Lo contrario: no destejer, equivaldría a hacer nudos en la prenda, a evadir los errores, a aceptar, indignamente, humillaciones.

\section{¿Por qué?}

¿Si duele/ hoy una trivialidad/ y mañana una espina lastima demasiado.// Si empiezan a cansar/ los temores, las fobias,/ las excusas del amado.// Si maltratan los límites/ y las cosas han cambiado.// Si algo se va achicando,/ por qué fingir no mirarlo?

De La sonrisa de Penélope y su costumbre del adiós.

No observar la propia existencia con una mirada crítica equivaldría a condenarnos a la amargura y al rencor. $\mathrm{Y}$ otro postulado de vida presente en mi poesía es ese: ser agradecida por lo que tengo y no andarme lamentando por lo que no tengo, como dice este poema:

\section{Como cuidar la viña}

Mi viña está en ladera fértil.// Con aires festivos de entusiasmo/ vivo cada uno de los tiempos de su cultivo.// Al cercarla, despedregarla,/ y plantarla de vides escogidas,/ la riego de cantos.// En la espera de las lluvias,/ construyo un lagar/ para exprimir el mosto.// Con las primeras aguas me deleito/ en el olor a tierra mojada.// Cuido cada uno de sus brotes/ y la alejo de la amenaza/ del cardo y los espinos.// Y cuando recojo el fruto,/ cada uva en mi boca/ destila su consistente gozo.//Y los canastos llenos/ proclaman el disfrute/ de cada momento del proceso.// Así en la vida,/ cada instante/ con gratitud por lo que depara,/ porque el lamento/ por lo que no se tiene/ obstaculiza el deleite de lo que se posee/ y priva de las mieses.

De Habitar la casa del tesoro 
Me resisto

Está ahí/ como para que yo palpe/ su sonrisa.// Pero/ en este juego de escondido,/ ...de no sé,/ ...de se me olvidó,/ ...de ahorita llego,/ lo que percibo/ es una mueca/ que inyecta en mis labios/ la palabra despedida,/ el desamor,/ la desesperanza,/ los pasos del adiós.// Me resisto:/ Para no claudicar/ de mi afán por la pareja en libertad,/ respetada, amada, cuidada,/ es más convincente la ausencia/ que la tribulación/ de compañías a medias.// Prefiero la certeza/ de un quebranto/ a la incertidumbre/ de este acaso.

De Aposentos del deseo

Otros poemas que plantean abiertamente la desazón respecto a las dificultades porque relaciones de parejas comprometidas y solidarias se construyan son los siguientes:

\section{Aullido de desesperanza}

Un aullido de desesperanza/ se agazapa/ en mi madrugada solitaria:// ¿Qué pasa con la comunión de espacios?/ ¡Que cada quien tenga los suyos!, ¡sí!,/ ¿pero por qué desalojarse de los de ambos?// ¿De dónde la energía que separa de lo amado?/¿De dónde la fuerza para ganarle la partida?// ¿Por qué las metas,/ la dignidad y los límites/ dan cabida al resentimiento?// ¿Por qué ampararse en lamentos y heridas/ y no en ruiseñores y auroras?// Por qué se aplazan/ los diálogos y las caricias?// ¿Por qué se disimula el éxodo/ del placer y el compromiso?//Por qué las historias se pueblan/ de adioses y distancias?// ¿Por qué el intento/ por moldear una pareja renovada/ resulta en un brote/ tan doloroso y subterráneo?// ¿Por qué tantos porqués y tan pocos milagros?

De Aposentos del deseo

Este poema se complementa con el siguiente:

\section{Es hora de milagros}

Varón que fuiste el violín de sus aguas,/ que festejaste su vestido de nardos y rosas,/ y con quien, con las manos juntas,/ ella llegó a la alborada,/ ¿hace cuánto tiempo/ no besás el lugar/ que más le amas?// ¿Hace cuánto tiempo/ no ponés tu tacto/ donde a ella más le place?// ¿Hace cuánto tiempo/ la abandonás/ a la caricia de la almohada?// ¿Hace cuánto tiempo/ la fábula de tus pies,/ que ella conoció en la época del clamor,/ en el anhelo devorador de la tierra sedienta de cosecha,/ ya no se aproxima a la comunión/ del aposento más íntimo?//Esposo,/ por qué hoy sos/ cual analfabeto ausente/ que ya no cabalga/ por la memoria de su piel/ ni discifra sus sueños de mil sabores/y solo acierta en señalar el desentono?// ¡Es hora de alerta!// Unite a ella/ en convivencia solidaria,/ dibujá mariposas en su vientre/ y rompé el espejo enmarcado.// Unite 
a ella/ por un amanecer en el abrazo,/ por un desayuno compartido en mantel de día festivo,/ por un recorrer, de la mano, las calles inesperadas.// El Señor, su Padre,/ quien la ama,/ te pregunta:// ¿Por qué se congeló tu ritmo/ y perdiste tu mirada?// El Señor, su Padre,/ quien la ama,/ te dice que arar ayer o mañana/ es arar a destiempo./ ¡Esta es la hora!/ La hora siempre es hoy,/ es el minuto, es el segundo de un detalle.// El Señor, tu Padre,/ quien te ama,/ te demanda que bañés sus soles,/ alumbrés sus atardeceres/ y descifrés sus anhelos,/ porque es hora/ de renunciar a las caparazones inservibles/ que amurallan la sensibilidad compartida./¡Es hora de recoger las cenizas/ y encender el fuego!// El Señor/ también te dice/ que lo que le des a ella,/Él lo recibe/ y te recuerda/ que ya no es tiempo/ de tantos porqués/ sino que es época de milagros.

De Habitar la casa del tesoro

La posición planteada en "Penélope" se refuerza o se repite en otros poemas del mismo libro, de los que a continuación transcribo tres, dos de los cuales son dedicados a una hija. Creo que esa posición de dignidad en la mujer, de afán por una pareja construida entre pares y en el marco del compromiso, del respeto y de la igualdad, se mantiene a lo largo de mi poesía.

\section{Aprende a volar}

Como la mariposa/ que sale del capullo/ ya tú, mi niña, quieres volar./ Explora la pradera./ Escoge bien las flores./ Si chupas néctar amargo, / sacúdelo en el vuelo./ Con tu sonrisa de ángel:/ ¡Aprende a volar!

De La sonrisa de Penélope y su costumbre del adiós

Este poema invita a la niña adolescente a explorar el mundo con valentía y sin que el temor a equivocarse sea el freno para vivir. Es proponerle a los hijos el ca- mino de la libertad, la sana independencia, con la convicción de haberlos preparado, en un trabajo lleno de amor y renuncia, para eso.

\section{Soy mujer}

Trataron de convencerme/ de mi vocación para el sacrificio,/ de mi invulnerabilidad ante el deseo,/ de cargar un fardo de culpas.// Muchos me soñaron/ como una sombra callada.// He recibido embustes./ He aceptado aplausos./ Me he equivocado.// Hice antesala/ esperando turno para una dádiva.// Transé.// Insospechada,/ espesa,/ la vigilia habitaba la bodega de mi casa./ Cual bombillo desnudo/ mientras yo sufría una pesadilla,/ alumbró mi cara.// Desperté/ jurándome fidelidad,/ con los ojos maltratados, en una calurosa mañana.// Desde ese día/ no ha sido nada fácil,/ pero en mis territorios/ se instaló la esperanza.// Recuperé mi orgullo de madre/ del que alguien quiso avergonzarme.// Defendí mi 
espacio en la lucha/ y en el trabajo.// Exigí una heredad/ para el cultivo/ de mi ser lleno de ansias,/ con algunos deseos concretos/ y otros... no tan inmediatos.// Mi heredad de mujer que precisa,/ también,/ la geografía del amado.

\section{De La sonrisa de Penélope \\ y su costumbre del adiós}

Este poema expresa el tránsito de una mujer ancestral, callada y sumisa, a una transgresora y comprometida con su propia vida. Este tránsito es un proceso histórico, una conquista de desgarre y de logros, una lucha presente siempre, constante. Una posición de vida no sólo ante la pareja, sino también ante los hijos e hijas, ante las relaciones de trabajo y de estudio, ante la vida como totalidad.

\section{"El amor es de valientes"}

Hija,/ pretendes/ encender un fuego luminoso,/ moldear un rústico refugio,/ desprenderte de la pompa,/ fracturar lo esperado,/ y atreverte a un frágil desgarramiento/ que se consolide luego/ en un vínculo enraizado.// Sólo acierto a decir/ que das un paso importante,/ que la historia es irreversible,/ que el afecto se construye/ y que es responsabilidad de ambos.// Que empiezan a arañar la vida/ y que es necesario desvestirla,/ y exigirle que detrás de cada plato,/ de cada silla, de cada espacio,/ esté el esfuerzo y la biografía de ambos.// También quiero decirte/ que te despreocupes del cálculo de lo eterno/ y del cálculo del minuto,/ que el amor es riesgo/ y arriesgarse es de valientes.

\section{De La sonrisa de Penélope y su costumbre del adiós}

De nuevo este poema muestra una relación de pareja que se construye en la igualdad y el esfuerzo mutuo. Una lucha de ahora y de mañana. Una mujer que se construye, que avanza, que se propone metas aún no alcanzadas, pero que ya no está donde estaba, como se plantea en el siguiente poema aún sin poemario:

\section{Desaparecer}

Un depósito dentro/ contenido por miedos prestados.// Una barrera/ que interfiere el reconocimiento/ del origen del temor.// Sueños apresados.// Una jaula/ que detiene el vuelo.// Viajes perennes/ en el tren de la culpa.// Madre víctima inválida niña bruja/ solterona menopáusica vieja:/ ¡Huellas en el rostro!/ ¡Heridas en el alma!/ ¡Cojeos en la caminata!// Cuánto coraje ha tenido/ al atreverse a ser ella misma/ al derribar ídolos/ al buscar sus sanos apoyos/ al protegerse en el amor/ al decidir un nuevo curso/ en el que desaprender/ y aprender no son tareas fáciles.// Todavía no ha llegado al destino,/ pero ya no está donde estaba./ Ahora,/ con el dominio de las semillas ocultas de su ser/ cultiva sus propios jardines/y se prepara para florecer. 
Como en la poesía se dejan ver nuestros anhelos y nuestras vivencias, en el poemario Habitar la casa del tesoro, aún inédito a pesar de que ya tiene más de tres años de terminado, expreso mi reconciliación con Dios y le canto a un Amado con mayúscula. Aquí los dos poemas de amor con los que cierro ese libro:

Soy vasija

Entre Salmos y Cantares

En las manos de mi Amado/ soy vasija.//Él,/ mi alfarero,/ me rodea con su escudo,/ afila mi espada/ y prepara mi arco.//Y me llena de palabras limpias/ como de plata refinada en horno de tierra/ y purificada siete veces.// Así,/ ilumina mi rostro/ y alegra mi casa.// Como a árbol plantado/ en su tierra predilecta/me cuida.// Para que mi fruto sea dulce/ y la sombra de mis ramas abundante,/ me riega.// Él es toda mi herencia./ Es mi copa.// En su reposo me deleito/ y en su presencia me gozo a plenitud./ Bajo la sombra de sus alas me cobija/ y su lecho es como panal de miel.// Mejores son sus amores que el vino./ Él es mi viña.// Sella mi corazón con brazas de fuego./ Prende llamas en mí,/ inapagables con otras/ que no sean sus aguas.// ¡Mi Amado es el más hermoso!// Por eso,/ para Él guardo/ mis mejores lirios,/ las uvas más jugosas, / la fragancia más silvestre,/ la melodía de más acordes/ y lo más apasionado de mi voz.

De Habitar la casa del tesoro

\section{Así quiero amarlo}

Con un aroma profundo de guayaba/ y con la fragancia de un rústico jardín,/ así quiero prenderme a mi Amado.// Con la soltura de las ramas del pino/ movidas por la brisa,/ así quiero danzar en su aliento./ Con la vistosidad de una llama del bosque/ en la copa del árbol,/ así quiero mostrarlo.// Con la laboriosidad de una hormiga,/ así quiero cuidarlo.// Con la certeza de la fidelidad,/ así quiero tomarlo.// Con el rugido de tigre acorralado,/ así quiero llamarlo.// Con el apego de una enredadera,/ así quiero abrazarlo.// Con la alegría de una novia en su boda,/ así quiero alabarlo.// Con la pasión de una enamorada,/ así quiero adorarlo.

\section{De Habitar la casa del tesoro}

Para terminar, quiero compartir una reflexión del poeta Carlos Francisco Monge y repetir algunas de sus ideas. Dice él: “...en el fondo, los escritores son seres solitarios; pero sueñan con participar de la sociedad, escriben en soledad para hablar a los otros."

Yo creo que eso es cierto y agrego que procurarse ese espacio de soledad para la escritura y, principalmente para la poesía, se hace difícil. Ciertamente la rutina del trabajo y la necesidad de "ganarse los frijoles" hacen que el acto creador deba ser pospuesto y engavetado en el lugar de lo desechable. Por ventura, con frecuencia, escribir se convierte en una necesidad tal que debe abrirse campo a la brava, quitándole espacio a otras ocupaciones, pues 
nuestra sociedad está lejos de concebir la escritura como un oficio del cual se pueda vivir, sigue siendo este quehacer un espacio de lo marginal y, dentro de lo marginal, la poesía es más marginal aún.

A pesar de esto, el escritor o la escritora se rebela contra el olvido y entra en la urgencia de mostrar el lado que está observando en las cosas maravillosamente cotidianas y en la prodigiosa realidad o irrealidad del mundo. Y, en este momento, en esa necesidad de ser leído, se tropieza con políticas editoriales para las cuales la poesía no resulta rentable, pues tiene pocos compradores. El escritor se va convirtiendo en una imagen que se vende $o$ no se vende en estrategias de mercado y muchos caen en el peligro de convertirse en "vedette" u ornamento de poder. En el deseo de lograr reconocimiento surge la tentación a premios y aplausos.

Parece que el camino de la publicación autogestionada, en editoriales pequeñas, se va abriendo paso, lo cual abre accesos a los excluidos y a los que puedan pagarla.

Como dice el poeta citado, ante este panorama, lo que le queda al escritor es la conciencia de su propia satisfacción. No se puede ser independiente, si se anda detrás de los premios, del éxito o del triunfo.

Espero que mi exposición los invite a ustedes a la lectura y al libro, de los míos o de los otros, pues leer un libro es apropiarse de otros mundos, dialogar con extraños y con los duendes propios, es una aventura que no hay que perderse.

\section{Referencias bibliográficas}

Calvo Oviedo, Marlen. La poesía de Marta Rojas. Una alternativa en la construcción de nuevos paradigmas del discurso poético de las mujeres. En Káñina Vol. XXXVI (2), 2002.

Monge, Carlos Francisco. Arte, literatura y sociedad. En Memoria. I Simposio Octavio Paz. Editado por Baco Teatro Danza, San José, Costa Rica. 1998.

Rojas, Marta Eugenia. La sonrisa de Penélope y su costumbre del adiós. Editorial de la Universidad de Costa Rica. 1993. Aposentos del deseo. Editorial de la Universidad de Costa Rica. 1996.

tesoro. Inédito.

Habitar la casa del

Preble-Niemi. El retrato poético de la hija de la "mujer moderna" centroamericana. En Scripta Humanística. USA. 1998. 
